\title{
New Insights into the Role of Chronic Inflammation and Cytokines in the Etiopathogenesis of Gastroenteropancreatic Neuroendocrine Tumors
}

\author{
Maja Cigrovski Berkovic ${ }^{a}$ Tamara Cacev $^{b}$ Tina Catela Ivkovic ${ }^{b}$ \\ Vanja Zjacic-Rotkvic ${ }^{a}$ Sanja Kapitanovic ${ }^{b}$ \\ a Department of Endocrinology, Diabetes and Metabolism 'Mladen Sekso', University Hospital Centre \\ 'Sestre milosrdnice', and 'Laboratory of Personalized Medicine, Divison of Molecular Medicine, \\ Institute Rudjer Boskovic, Zagreb, Croatia
}

\section{Key Words}

Gastroenteropancreatic neuroendocrine tumor .

Inflammation · Cytokines · Tumorigenesis

\begin{abstract}
Although previously considered rare, recent epidemiological studies have revealed that the incidence $(3.6 / 100,000)$ and prevalence $(35 / 100,000)$ of gastroenteropancreatic neuroendocrine tumors (GEP-NETs) has increased over the past few decades. Despite the progress in the understanding of GEP-NET molecular biology, there is still little advance in the early diagnosis due to lack of specific tumor markers. As the tumors are mostly detected in their late stage, they are not well controlled by either biotherapy or conventional chemotherapy, and thus represent a significant clinical issue. Chronic inflammation has been implicated in the development of GEP-NETs. This review presents recent findings that link pro-inflammatory cytokines to the molecular basis of GEP-NET tumorigenesis, leading to a more personalized approach to disease management and therapy.
\end{abstract}

(c) 2014 S. Karger AG, Basel (c) 2014 S. Karger AG, Basel

0028-3835/14/0992-0075\$39.50/0

\section{Introduction}

Gastroenteropancreatic neuroendocrine tumors (GEP-NETs) are a heterogeneous group of neoplasms that arise from the cells of the diffuse endocrine system scattered through mucosa of the gastrointestinal tract and pancreas $[1,2]$. Although considered rare, GEP-NETs have an incidence of 3.6/100,000 and an estimated prevalence of 35/100,000 [3].

Due to lack of symptoms in the early stages, frequent non-specific gastrointestinal symptoms and lack of specific tumor markers, GEP-NETs are difficult to diagnose. The delay in timely diagnosis often results in patients presenting with advanced disease and a poor prognosis quoad vitam. Consequently, a large proportion of tumors exhibit metastases at the time of diagnosis and at that point are not well controlled by either biotherapy or conventional chemotherapy [4]. Therefore, there is still an unmet need for earlier GEP-NET diagnosis.

Chromogranin A (CgA) is currently the best general tumor serum and tissue marker expressed in $80-90 \%$ of patients with GEP-NETs. Its value lies in its universal se-

\section{KARGER}

E-Mail karger@karger.com

www.karger.com/nen
Maja Cigrovski Berkovic

Department of Endocrinology, Diabetes and Metabolism 'Mladen Sekso'

University Hospital Centre 'Sestre milosrdnice'

Vinogradska 29, HR-10000 Zagreb (Croatia)

E-Mail mberkovi@globalnet.hr 
cretion by the majority of neuroendocrine cells that persist after malignant transformation. Unfortunately, CgA is also secreted in a variety of non-NET-related pathologic conditions, so in clinical practice, due to limitations in sensitivity, specificity and reproducibility, it is a moderately effective tumor biomarker in the management of GEP-NETs $[3,5]$.

Together with $\mathrm{CgA}$, proliferation marker $\mathrm{Ki}-67$ is a universal marker of cell proliferation and biological behavior, and is important for tumor grading and classification [6]. The identification of effective biomarkers to improve GEP-NET diagnosis, as well as to assess treatment efficacy, relapse and prognosis, is high on the list of priorities in GEP-NET research and markers such as neurokinin and pancreastatin are being evaluated [7-9].

This overview focuses on the role of chronic inflammation and pro-inflammatory cytokines in GEP-NETs, and their possible role as disease prognostic markers. It is not intended to encompass every aspect of GEP-NET etiopathology but to provide an overview in the abovementioned areas as well as to discuss the authors' own results in the field.

\section{Gastroenteropancreatic Neuroendocrine Tumors}

Carcinoids, slow-growing tumors, were first recognized in 1907, which laid the basis for the understanding of GEP-NETs. However, molecular changes underlying such tumors are still not very well understood. At the beginning, carcinoids were thought to be rare, and as the name suggests, of benign behavior. Since then the advances made in the understanding of neuroendocrine cell physiology, pathophysiology, and tumor analysis at histological and molecular levels have revealed the full complexity of the disease. However, due to this complex heterogeneity, little or no survival increase has been achieved over the years. Therefore, GEP-NETs still represent a significant clinical issue while due to a lack of specific early biomarkers as many as $50-70 \%$ are metastatic at the time of diagnosis and there is a paucity of effective therapy in the later stages [10].

Quite a few tumor characteristics were taken into account in order to classify GEP-NETs and to predict tumor prognosis [11-13]. According to current knowledge, there are at least 17 different neuroendocrine cell types distributed throughout the gastrointestinal tract and pancreas, which could all be taken into account as potential tumor progenitors (fig. 1). In order to address this complexity in everyday clinical practice, common clinical diagnostic and prognostic criteria have to be established between pathologists and clinicians [14-21]. The most prominent features that are still used in the literature concerning GEP-NETs are: embryogenetic origin of the tumor, tumor size and differentiation, presence of angio- or lymphatic invasion, presence of local or distant metastases and functional activity of tumor cells, but as molecular profiling may enhance tumor classification schemes, efforts are being made to include molecular features of tumors into current classifications $[22,23]$.

The first insight into the genomic basis of GEP-NETs was presented by the discovery of MEN-1 genetic variants (MEN-1) during the research studies on inherited forms of GEP-NETs, primarily occurring as a part of multiple endocrine neoplasia type 1 (MEN-1) syndrome. However, $M E N-1$ mutations can explain the genetic mechanisms present in only a small proportion of tumors, while the biology of the majority of more common, sporadic GEPNET forms still remains poorly understood [24]. Since $M E N-1$, many different genes have been investigated for their potential role in GEP-NET development and progression, and new molecular profiles of gastrointestinal (GI-NETs) and pancreatic neuroendocrine tumors (pNETs) were subsequently described $[23,25]$.

Current knowledge in this field shows that frequent chromosomal gains occur on chromosomes 7 and 20, the former also associated with metastases, together with losses on chromosomes 2, 6q, 21q, and Y in pNETs. On the other hand, comparative genomic hybridization studies of GI-NETs show frequent gains on chromosomes 17 and 19, while a frequent loss was detected on chromosome 18. These findings further distinguish the different molecular genetic background of these two tumors [26-28].

In addition, several new potential GEP-NET biomarkers have emerged through molecular profiling studies on neuroendocrine tumors. For instance, in the study of Leja et al. [29], paraneoplastic antigen Ma2 (PNMA2), testican-1 precursor (SPOCK1), serpin A10 (SERPINA10), glutamate receptor ionotropic AMPA 2 (GRIA2), G protein-coupled receptor 112 (GPR112) and olfactory receptor family 51 subfamily E member 1 (OR51E1) have been identified as potential markers of neuroendocrine carcinomas. In the study of Duerr et al. [23], differentially expressed genes in pNETs versus GI-NETs have been identified. Adenylate cyclase 2 (ADCY2), nuclear receptor subfamily 4, group A, member 2 (NR4A2), FEV and growth arrest and DNA-damage-inducible, $\beta$ (GADD45b) were upregulated in the malignant group of pNETs. Malignant ileal GI-NETs presented a differ-
76

Neuroendocrinology 2014;99:75-84 DOI: $10.1159 / 000362339$
Cigrovski Berkovic/Cacev/Catela Ivkovic/ Zjacic-Rotkvic/Kapitanovic 
Fig. 1. Clinical classification of GEP-NETs.

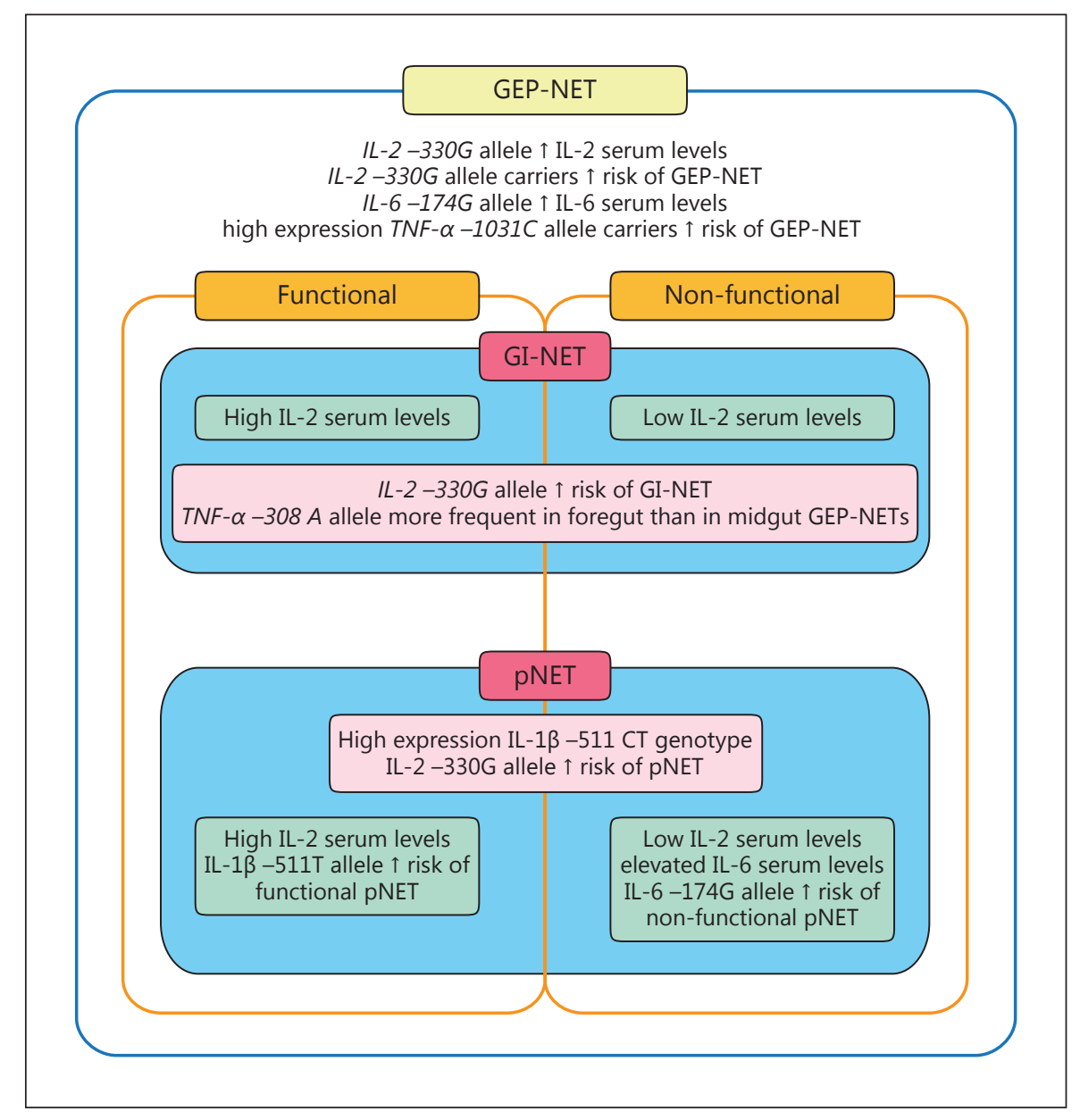

ent molecular expression signature with upregulation of extracellular matrix protein 1 (ECM1), vesicular monoamine member 1 (VMAT1), galectin 4 (LGALS4), and RET.

More so, epigenetic changes have also been identified to have an important role in the development and progression of GEP-NETs. Indeed, numerous miRNAs as well as specific miRNA signatures have been analyzed in order to predict the clinical outcome of lung neuroendocrine tumors and small intestinal neuroendocrine tumors. For instance, miRNA-133a has been identified as a marker of progression from primary to metastatic carcinoid tumors with a possible diagnostic and/or prognostic value in midgut carcinoid tumors [30, 31].

In the last few years, both national and international societies with multidisciplinary panels have published diagnostic and treatment guidelines for GEP-NETs which include surgery, bio- and chemotherapy, radionuclide therapy as well as new targeted therapies [32-
35]. Despite the progress in the understanding of GEPNET molecular biology, there is still little advance in their early diagnosis and we are still lacking a definition of malignant molecular profile of tumors. This is in part due to the incomplete understanding of underlying signalling pathways as well as the lack of biochemical markers/screening tests which results in the delay of GEPNETs' clinical management. Consequently, a large proportion of tumors exhibit metastases at the time of diagnosis and at that point are not well controlled by either biotherapy or conventional chemotherapy [36, 37].

Introduction and development of somatostatin (sst) analogues and interferon (IFN)- $\alpha$ substantially ameliorated life of GEP-NET patients with grave symptomatology, caused by hormone overproduction and secretion. The latter, immune-mediated treatment with IFN- $\alpha$, set additional ground for our research of chronic inflammation in the setting of GEP-NETs $[14,15]$. IFNs exert an- 
titumor effects through different mechanisms, and in the presence of NETs they additionally induce upregulation of sst receptors. Although IFN treatment is associated with some side effects, it is quite tolerable at the dose ranges studied in NETs. At present, biotherapy (sst analogues and IFNs) is a preferred treatment option in case of well-differentiated and slow-growing tumors. An sst analogue is induced in case of positive sst receptors, while in the case of negative sst receptors, IFN- $\alpha$ is administered, or they are used together to reach symptomatic improvement or disease stability [38-41]. More recently a direct anti-tumor effect of sst analogue octreotide has been demonstrated in patients with low-grade metastatic midgut NETs, regardless of tumor functional status. The most frequently observed response was stable disease, and patients with the relatively low tumor burden seemed to benefit the most. Nonetheless, the treatment of each individual tumor is often complex and requires multidisciplinary expertise of endocrinologists, gastroenterologists, surgeons, oncologists, nuclear medicine specialists and pathologists $[40,42]$.

\section{Chronic Inflammation and Cytokine Genetics in Tumorigenesis}

The link between inflammation and cancer was described in the 19th century by Virchow who discovered lymphocytes infiltrated into neoplastic tissue [43, 44]. Moreover, inflammation affects immune surveillance and responses to therapy; therefore, modulating the immune response may be an alluring target for therapeutic intervention [45].

Carcinogenesis in the gastrointestinal tract and pancreas is often associated with chronic inflammation. For example, polymorphisms in genes coding for inflammatory mediators are associated with an increased risk of gastric cancer. A particularly striking example of the mentioned link is seen in the inflammatory bowel disease associated with an elevated risk of colorectal cancer or chronic pancreatitis potentiating the development of pancreatic adenocarcinoma [46, 47]. Similar observations have been made in inflammatory bowel disease patients developing gastrointestinal neuroendocrine tumors [48-53].

The exact mechanism by which chronic inflammation promotes tumor growth is still not completely understood. During tumorigenesis the host-mediated anti-tumor activity is suppressed, while pro-inflammatory actions prevail ultimately supporting tumor growth, angio- genesis, invasion and metastasis $[54,55]$. Importantly, cytokines shape the tumor microenvironment into either favorable or suppressive for tumor growth. The direction in which the balance is tipped - either towards tumor suppression or progression - depends much on the cytokine profile that is predominantly expressed in the tumor microenvironment. Several cytokines, such as TNF- $\alpha$, IL$1 \alpha$, IL-1 $\beta$, IL-6, IL-10, IL-12, IL-17 and IL-23, are responsible for this polarization, and of these the involvement of TNF- $\alpha$, IL- 6 and IL-17 has been continuously proven in tumor growth and promotion [56].

Pro-inflammatory cytokines, chemokines, growth factors, prostaglandins, and reactive oxygen and nitrogen species act as immune system messengers in feed-forward loops present in the nuclear factor- $\kappa \mathrm{B}(\mathrm{NF}-\kappa \mathrm{B})$ and signal transducers and activator of transcription (STAT3) pathways $[44,53]$.

STAT3 activation is essential for initiation and progression of majority of solid malignancies $[57,58]$. Persistent STAT3 activation in malignant cells stimulates cell proliferation and survival, angiogenesis, invasion, and tumor-promoting inflammation. STAT3 orchestrates tumor-associated inflammation by upregulating chemokines capable of attracting immune and inflammatory cells that further propagate STAT3 activity through production of mainly IL- 6 and IL- $1 \beta$ [57-59]. Recruited immune cells as well as neoplastic cells continue to produce cytokines that activate oncogenic transcription factors, sustaining tumor-associated inflammation. This implies that drugs that disrupt tumor-associated inflammation could have significant therapeutic and preventive effects in a variety of cancers, regardless of their origin [60].

The activation of NF- $\kappa$ B pathway in cancer cells regulates either cell survival during early tumor promotion or induces the transcription of genes that encode pro-inflammatory cytokines, including TNF- $\alpha$ and IL-6, which further affect tumor growth through the paracrine induction of NF- $k B$ and STAT3 $[61,62]$.

As STAT3 and NF- $\kappa$ B pathways control genes necessary for angiogenesis, mainly vascular endothelial growth factor (VEGF), they influence the ability of tumor cells to invade and metastasize $[63,64]$. NF- $\mathrm{KB}$ and STAT3 signalling pathways are persistently activated in various malignancies, and the most common mechanism of their induction is by an excess of cytokines provided in an autocrine or paracrine loop. In general, cytokines can be divided into those that are pro-inflammatory (i.e. IL-1, IL-6, IL-8, IL-11, IL-12, IL-18, IL-23, TNF- $\alpha$ ) and antiinflammatory (i.e. IL-4, IL-10, IFN- $\alpha$, IFN- $\beta$ ); however, it
Cigrovski Berkovic/Cacev/Catela Ivkovic/ Zjacic-Rotkvic/Kapitanovic 
has become clear that many of these molecules can have dual roles. TNF- $\alpha$ and IL- $1 \beta$ are essential in the initiation of chronic inflammation, and their role via the activation of NF- $\kappa \mathrm{B}$ pathway has provided a strong link to cancer [44].

\section{Inflammation in GEP-NETs}

Research efforts over the past few decades have shown that GEP-NETs occur more frequently in the settings of chronic inflammation. Indeed, it was shown that enteroendocrine cells can be hyperstimulated by chronic inflammation, which leads to their hyperplasia and neoplastic transformation [65-68].

Studies of neuroendocrine tumors imply important role of cytokines such as IL-1 in the directing cancer cells to either neuroendocrine differentiation or to development of adenocarcinoma [69-71] while exogenously added IL- 1 causes a decrease in CgA and simultaneous increase in CEA secretion. These findings therefore suggest a direct relationship between IL-1 and CEA expression as well as inverse relationship between IL-1 and NE differentiation. Additionally, IL-2 has an established role in gastrointestinal hormone synthesis and secretion [72]. Moreover, GEP-NETs are highly vascularized and they express different growth factors, cytokines and tyrosine kinase receptors that are currently used as markers of tumor malignant potential [73] and targets for new chemotherapeutic agents [74].

\section{Cytokine Genetics in GEP-NETs}

Several pro-inflammatory cytokines have been implicated in the development of carcinoid tumors [75-80], and in case of metastatic carcinoids an additional prognostic role of cytokines was noticed [81].

The cytokine genes are highly polymorphic, and different polymorphisms, mostly single nucleotide polymorphisms (SNPs), influence the regulation of their expression and function. In addition, genetic polymorphisms have in recent years been identified as important modifying factors of disease susceptibility and prognosis. Although most polymorphisms are functionally neutral, some have effects on gene expression regulation or influence the function of the encoded protein. These regulatory SNP polymorphisms, despite being of low penetrance, directly influence interindividual variation in the magnitude of cytokine response, and could contribute to

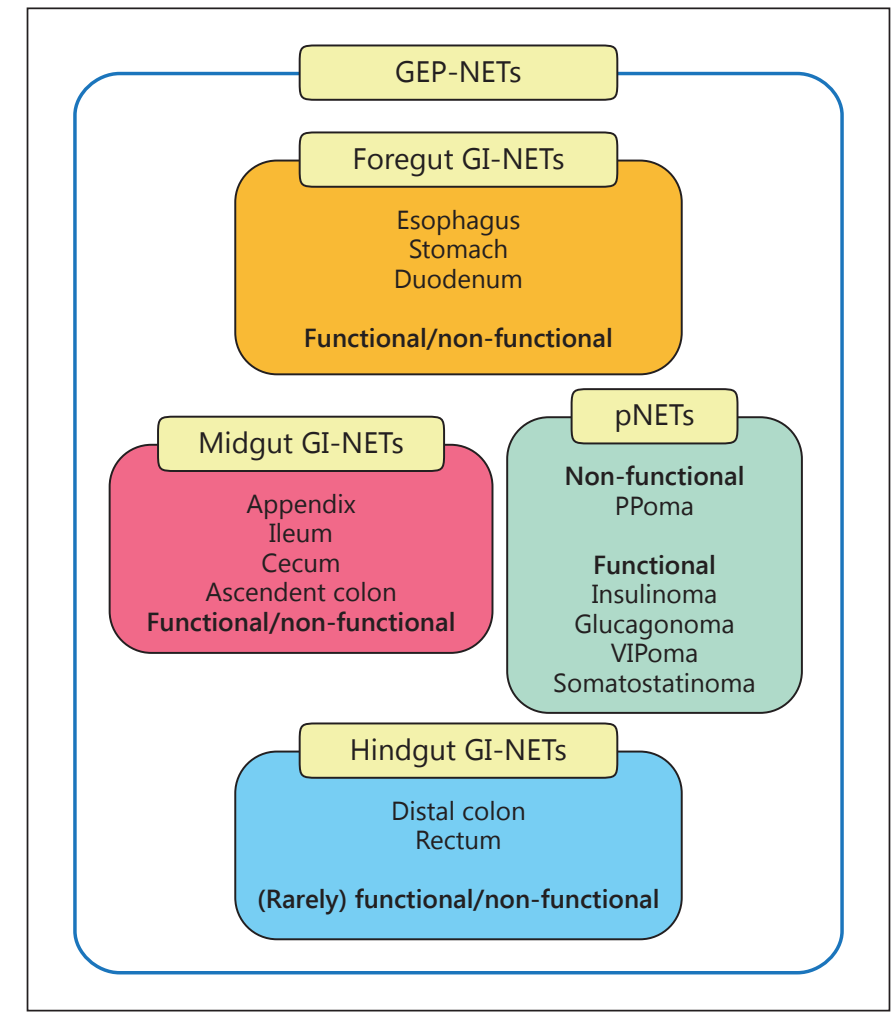

Fig. 2. Overview of our results on the role of cytokine in the etiopathogenesis of GEP-NETs.

differences between individuals in susceptibility to and prognosis of cancer. Consequently, deregulation of cytokine production can influence tumor progression as well as host anti-tumor immunity [82].

During the past decade we have investigated the potential association between SNP polymorphisms in cytokine genes and susceptibility to both pNET and GI-NET tumors. In our work, we have examined the role of several promoter SNPs in the TNF- $\alpha, I L-1 \beta, I L-2$ and $I L-6$ genes. These polymorphisms were chosen based on their influence on cytokine expression regulation and their association with susceptibility to different tumors of gastrointestinal tract and pancreas [83]. We have also analyzed the role of these inflammatory cytokines as novel potential tumor markers by comparison of their serum levels with known neuroendocrine prognostic and diagnostic markers in GEP-NET patients, as well as with individual cytokine SNP profiles.

In our pioneer study in this field we have examined the role of pro-inflammatory cytokine TNF- $\alpha$, IL-6, IL- $1 \beta$ and IL-2 in GEP-NETs (fig. 2). 
Our study has shown that TNF- $\alpha$ and $I L-2$ are associated with GEP-NET development. Specifically, TNF- $\alpha$ $-1031 C$ and $I L-2-330 G$ allele increase one's overall susceptibility to develop GEP-NETs. On the other hand, $T N F-\alpha-308 A$ allele is specific only for susceptibility to foregut GI-NET. Moreover, $I L-2-330$ TG and GG and $I L-6-174 C G$ and $G G$ genotypes contribute to higher IL-2 and IL- 6 serum levels in GEP-NET patients. When serum levels of these cytokines are compared to standard neuroendocrine markers such as $\mathrm{CgA}$ (ubiquitous marker of both functioning and non-functioning GEP-NETs) and 5-hydroxyindoleacetic acid (5-HIAA) (elevated primarily in metastatic carcinoid tumors or serotonin-producing GEP-NETs), then IL-2 was more sensitive than 5-HIAA, and $\mathrm{CgA}$ in GEP-NET diagnostics $[84,85]$.

Especially interesting are results concerning the pNETs. These tumors can either occur sporadically but can also be a part of syndromes of inherited multiple endocrine gland tumors. In latter case, there is an increased risk of tumor development in patient's family members. $M E N-1$ genetic variants can help to detect potential carriers of disease, but pNETs occurring as a part of MEN-1 are often non-functioning and diagnosed late. Moreover, tumors can be multiple and often small, with uncertain malignant potential and their surgical treatment is often challenging and potentially mutilating [86-88]. Therefore, the development of new and early prognostic markers as well as elucidation of potential susceptibility genes is of primary scientific and clinical interest.

According to several studies, pro-inflammatory cytokines were detected in pNET tissue suggesting their possible involvement in their etiology [89-91]. Our results show involvement of IL- 6 and IL- $1 \beta$ in pNET development. According to SNP analyses, $I L-6-174 C G$ and $G G$ genotype carriers and IL-1 $\beta-511 /+3954$ CTCC carriers were at risk of developing non-functional pNETs $[84,85$, 92], while IL- $1 \beta-511 /+3954$ CTCT carriers were prone to development of functional pNETs [93]. Moreover, IL-6 GG genotype correlated with IL-6 serum levels that were significantly higher in patients with non-functioning pNETs.

In conclusion, the results of many research studies have defined cytokines as one of the most important modifying factors in development, progression and prognosis of malignant tumors. In addition, many new antineoplastic drugs have been developed to target specific growth factor-induced signalling; especially interesting are monoclonal antibodies producing pharmacological blockade of cytokines, growth factors and/or protein kinases. The mentioned agents targeting VEGF, tyrosine kinase and mammalian target of rapamycin (mTOR) pathways which are recognized as relevant targets in the neuroendocrine tumor biology are currently under investigation for treatment of GEP-NET patients. A serine-threonine kinase mTOR is an integral part of several signalling pathways, including the signaling via VEGF [94], and mTOR inhibitors everolimus and temsirolimus have been evaluated in clinical trials for the treatment of patients with metastatic NETs. Especially promising were the results in patients with advanced pNETs, leading to the approval of everolimus in the treatment of progressive $\mathrm{pNET}$ in patients with unresectable, locally advanced or metastatic disease [95]. Specific targeted agents interacting with the VEGF pathway including direct VEGF blockers such as bevacizumab and multitargeted tyrosine kinase inhibitors such as sunitinib were evaluated for the treatment of patients with NETs. Based on the results of clinical trials, sunitinib was approved for the treatment of patients with unresectable or metastatic well-differentiated pNETs with disease progression [96, 97]. Moreover, in individual cases, both mTOR inhibitors and sunitinib have proven successful in control of hormone hypersecretion by NETs [98, 99]. These novel agents are showing encouraging results in the prolongation of progression-free survival and improvement of hypersecretory syndromes. As a consequence of these advancements in therapy, pNETs are becoming a chronic condition for numerous patients. Currently, identification of biomarkers of the biologic activity of such targeted therapies as well as markers of response and prognosis is of utmost importance and it might help in selecting patients that can benefit most [100-103]. Among potential prognostic markers that correlate with clinical outcomes and therapy resistance are the VEGF pathway proteins and IL-8, but they are not yet integrated into clinical practice [101]. Additionally, post-transcriptional modifications of mTOR signalling pathways, especially alternative splicing, and detection of alternatively spliced isoforms of key substrates such as S6K1, might be used to predict the sensitivity of tumors to mTOR inhibitors, enabling better choices of drug treatment in the clinic [104].

\section{Conclusion}

Although a link between inflammation and cancer has been recognized for quite some time, the complex network of interactions between different immune cell populations, tumor cells as well as cells in the tumor micro-
Cigrovski Berkovic/Cacev/Catela Ivkovic/ Zjacic-Rotkvic/Kapitanovic 
environment is still far from being completely deciphered. This dynamic milieu consists of many factors with possibly antagonistic and synergistic effects depending upon the given context of different tumor type, tumor microenvironment as well as time point of tumor development and progression. Recent advances in high-throughput technologies have opened a new avenue of research possibilities uniting different -omics approaches and combining the obtained results with clinical data [105]. This approach will be especially important for diagnosis and prognosis of tumors with heterogeneous clinical presentation like GEP-NETs.

Indeed, constant efforts are being made to elucidate molecular genetic changes responsible for both GI-NET and pNET development and progression, but we are still very far from defining a molecular profile of malignant GEP-NETs.

In our proposed model, cytokine genotypes and corresponding high serum values modulate GEP-NET tumorigenesis. TNF- $\alpha-1031$ polymorphism is associated with the susceptibility to GEP-NET development. Genotypes and serum values of IL-2 may add a new step toward distinguishing functional from non-functional GEPNETs. IL- $1 \beta-511$ polymorphism can lead to pNET susceptibility while IL-1 $\beta-511$ high expression allele is more frequent among patients with functional pNET. Also IL-6 -174 polymorphisms add to susceptibility of pNET development, and elevated IL-6 serum levels are an important biomarker of non-functional pNETs.

In this review we have summarized the results of our 10 -year research and tried to propose a potential model of the role of cytokines in GEP-NET tumorigenesis, which could be used for a more personalized approach to management and therapy of these types of tumors. Future studies on angiogenic models as well as cell culture models of primary tumors and hematogenic and lymphogenic metastases of GEP-NETs will clearly be warranted in order to further elucidate the relationship between proand anti-inflammatory cytokines in GEP-NET patients.

\section{Acknowledgement}

This work was supported by the Croatian Ministry of Science, Education and Sport (grant Nos. 134-1342428-0491 and 0980982464-2508).

\section{Disclosure Statement}

The authors have no conflicts of interest to disclose.

\section{References}

1 Starker LF, Carling T: Molecular genetics of gastroenteropancreatic neuroendocrine tumours. Curr Opin Oncol 2009;21:29-33.

- Turaga KK, Kvols LK: Recent progress in the understanding, diagnosis, and treatment of gastroenteropancreatic neuroendocrine tumours. CA Cancer J Clin 2011;61:113-132.

3 Modlin IM, Drozdov I, Kidd M: The identification of gut neuroendocrine tumor disease by multiple synchronous transcript analysis in blood. PLoS One 2013;8:e63364.

4 Castellano D, Salazar R, Raymond E: Future perspectives on neuroendocrine tumours. Cancer Metastasis Rev 2011;30(suppl 1):3540.

5 Lawrence B, Gustafsson BI, Kidd M, Pavel M, Svejda B, Modlin IM: The clinical relevance of chromogranin A as a biomarker for gastroenteropancreatic neuroendocrine tumors. Endocrinol Metab Clin North Am 2011;40:111134.

6 Lindholm DP, Oberg K: Biomarkers and molecular imaging in gastroenteropancreatic neuroendocrine tumors. Horm Metab Res 2011:43:832-837.
7 Singh S, Law C: Chromogranin A: a sensitive biomarker for the detection and post-treatment monitoring of gastroenteropancreatic neuroendocrine tumors. Expert Rev Gastroenterol Hepatol 2012;6:313-334.

8 Turner GB, Johnston BT, McCance DR, McGinty A, Watson RGP, Patterson CC, Ardill JES: Circulating markers of prognosis and response to treatment in patients with midgut carcinoid tumours. Gut 2006;55:1586-1591.

-9 O’Dorisio TM, Krutzik SR, Woltering EA, Lindholm E, Joseph S, Gandolfi AE, Wang Y-Z, Boudreaux JP, Vinik AI, Go VLW, Howe JR, Halfdanarson T, O'Dorisio MS, Mamikunian G: Development of a highly sensitive and specific carboxy-terminal human pancreastatin assay to monitor neuroendocrine tumor behavior. Pancreas 2010;39:611-616.

10 Modlin IM, Oberg K, Chung DC, Jensen RT, de Herder WW, Thakker RV, Caplin M, Delle Fave G, Kaltsas GA, Krenning EP, Moss SF, Nilsson O, Rindi G, Salazar R, Ruszniewski P, Sundin A: Gastroenteropancreatic neuroendocrine tumours. Lancet Oncol 2008;9:61-72.
1 Wiedenmann B, John M, Ahnert-Hilger G, Riecken EO: Molecular and cell biological aspects of neuroendocrine tumours of the gastroenteropancreatic system. J Mol Med 1998; 76 637-647.

12 Modlin IM, Lye KD, Kidd M: A 5-decade analysis of 13,715 carcinoid tumours. Cancer 2003;97:934-959.

13 Barakat MT, Meeran K, Bloom SR: Neuroendocrine tumours. Endocr Relat Cancer 2004; 11:1-18.

14 Vinik AI, Woltering EA, Warner RR, Caplin M, O'Dorisio TM, Wiseman GA, Coppola D, Go VL; North American Neuroendocrine Tumor Society (NANETS): NANETS consensus guidelines for the diagnosis of neuroendocrine tumor. Pancreas 2010;39:713-734.

15 Schimmak S, Svejda B, Lawrence B, Kidd M, Modlin IM: The diversity and commonalities of gastroenteropancreatic neuroendocrine tumours. Langebecks Arch Surg 2011;396: 273-298.

16 Pape UF, Jann H, Müller-Nordhorn J, Bockelbrink A, Berndt U, Willich SN, Koch M, Röcken C, Rindi G, Wiedenmann B: Prognostic relevance of a novel TNM classification system for upper gastroenteropancreatic neuroendocrine tumors. Cancer 2008;113:256-265. 
17 Delle Fave G, Kwekkeboom DJ, Van Cutsem E, Rindi G, Kos-Kudla B, Knigge U, Sasano H, Tomassetti P, Salazar R, Ruszniewski P: ENETS consensus guidelines for the management of patients with gastroduodenal neoplasms. Neuroendocrinology 2012;95:74-87.

$\checkmark 18$ Caplin M, Sundin A, Nillson O, Baum RP, Klose KJ, Kelestimur F, Plöckinger U, Papotti M, Salazar R, Pascher A: ENETS consensus guidelines for the management of patients with digestive neuroendocrine neoplasms: colorectal neuroendocrine neoplasms. Neuroendocrinology 2012;95:88-97.

$\checkmark 19$ Jensen RT, Cadiot G, Brandi ML, de Herder WW, Kaltsas G, Komminoth P, Scoazec J-Y, Salazar R, Sauvanet A, Kianmanesh R: ENETS consensus guidelines for the management of patients with digestive neuroendocrine neoplasms: functional pancreatic endocrine tumor syndromes. Neuroendocrinology 2012; 95:98-119.

20 Pape U-F, Perren A, Niederle B, Gross D, Gress T, Costa F, Arnold R, Denecke T, Plöckinger U, Salazar R, Grossman A: ENETS consensus guidelines for the management of patients with neuroendocrine neoplasms from the jejuno-ileum and the appendix including goblet cell carcinomas. Neuroendocrinology 2012;95:135-156.

-21 Pavel M, Baudin E, Couvelard A, Krenning E, Öberg K, Steinmüller T, Anlauf M, Wiedenmann B, Salazar R: ENETS consensus guidelines for the management of patients with liver and other distant metastases from neuroendocrine neoplasms of foregut, midgut, hindgut, and unknown primary. Neuroendocrinology 2012;95:157-176.

22 Klöppel G: Classification and pathology of gastroenteropancreatic neuroendocrine neoplasms. Endocr Relat Cancer 2011;18:S1-S16.

-23 Duerr EM, Mizukami Y, Ng A, Xavier RJ, Kikuchi H, Deshpande V, Warshaw AL, Glickman J, Kulke MH, Chung DC: Defining molecular classifications and targets in gastroenteropancreatic neuroendocrine tumours through DNA microarray analysis. Endocr Relat Cancer 2008; 15:243-256.

-24 Marx SJ, Agarwal SK, Kester MB, Heppner C, Kim YS, Skarulis MC, James LA, Goldsmith PK, Saggar SK, Park SY: Multiple endocrine neoplasia type 1: clinical and genetic features of the hereditary endocrine neoplasias. Recent Prog Horm Res 1999;54:397-438.

-25 Perren A, Anlauf M, Komminoth P: Molecular profiles of gastroenteropancreatic endocrine tumours. Virchows Arch 2007;451:S39S46.

26 Zikusoka MN, Kidd M, Eick G, Latich G, Modlin IM: The molecular genetics of gastroenteropancreatic neuroendocrine tumours. Cancer 2005;104:2292-2309.

-27 Arnold CN, Sosnowski A, Schmitt-Graff A, Arnold R, Blum HE: Analysis of molecular pathways in sporadic neuroendocrine tumours of the gastro-entero-pancreatic system. Int J Cancer 2007;120:2157-2164.
8 Öberg K: Genetics and molecular pathology of neuroendocrine gastrointestinal and pancreatic tumors (gastroenteropancreatic neuroendocrine tumors). Curr Opin Endocrinol Diabetes Obes 2009;16:72-78.

-29 Leja J, Essaghir A, Essand M, Wester K, Oberg K, Tötterman TH, Lloyd R, Vasmatzis G, Demoulin JB, Giandomenico V: Novel markers for enterochromaffin cells and gastrointestinal neuroendocrine carcinomas. Mod Pathol 2009;22:261-272.

30 Ruebel K, Leontovich AA, Stilling GA, Zhang S, Righi A, Jin L, Lloyd RV: MicroRNA expression in ileal carcinoid tumors: downregulation of microRNA-133a with tumor progression. Mod Pathol 2010;23:367-375.

-31 Li SC, Essaghir A, Martijn C, Lloyd RV, Demoulin JB, Oberg K, Giandomenico V: Global microRNA profiling of well-differentiated small intestinal neuroendocrine tumors. Mod Pathol 2013;26:685-696.

32 Ramage JK, Ahmed A, Ardill J, Bax N, Breen DJ, Caplin ME, Corrie P, Davar J, Davies AH, Lewington V, Meyer T, Newell-Price J, Poston G, Reed N, Rockall A, Steward W, Thakker RV, Toubanakis C, Valle J, Verbeke C, Grossman $A B$; UK and Ireland Neuroendocrine Tumour Society: Guidelines for the management of gastroenteropancreatic neuroendocrine (including carcinoid) tumours (NETs). Gut 2012;61:6-32.

33 Eriksson B, Klöppel G, Krenning E, Ahlman $\mathrm{H}$, Plöckinger U, Wiedenmann B, Arnold R, Auernhammer C, Körner M, Rindi G, Wildi $S$; Frascati Consensus Conference Participants: Consensus guidelines for the management of patients with digestive neuroendocrine tumors - well-differentiated jejunal-ileal tumor/carcinoma. Neuroendocrinology 2008;87:8-19.

34 Clark OH, Benson AB 3rd, Berlin JD, Choti MA, Doherty GM, Engstrom PF, Gibbs JF, Heslin MJ, Kessinger A, Kulke MH, Kvols L, Salem R, Saltz L, Shah MH, Shibata S, Strosberg JR, Yao JC; NCCN Neuroendocrine Tumors Panel Members: NCCN Clinical Practice Guidelines in Oncology: neuroendocrine tumors. J Natl Compr Canc Netw 2009;7: 712-747.

35 Öberg K, Jelic S; ESMO Guidelines Working Group: Neuroendocrine gastroenteropancreatic tumors: ESMO clinical recommendation for diagnosis, treatment and follow-up. Ann Oncol 2009;20:150-153.

36 Modlin IM, Oberg K: A Century of Advances in Neuroendocrine Tumour Biology and Treatment. Hannover, Felsenstein CCCP, 2008.

37 Chan JA, Kulke MH: Progress in the treatment of neuroendocrine tumours. Curr Oncol Rep 2009;11:193-199.

38 Hofland LJ, de Herder WW, Waaijers M, Zuijderwijk J, Uitterlinden P, van Koetsveld PM, Lamberts SW: Interferon- $\alpha_{2 a}$ is a potent inhibitor of hormone secretion by cultured human pituitary adenomas. J Clin Endocrinol Metab 1999;84:3336-3343.
39 Fazio N, de Braud F, Delle Fave G, Öberg K: Interferon- $\alpha$ and somatostatin analog in patients with gastroenteropancreatic neuroendocrine carcinoma: single agent or combination? Ann Oncol 2007;18:13-19.

40 Lawrence B, Gustafsson BI, Kidd M, Modlin I: New pharmacologic therapies for gastroenteropancreatic neuroendocrine tumors. Gastroenterol Clin North Am 2010;39:615-628.

41 Strosberg JR, Cheema A, Larry K, Kvols LK: A review of systemic and liver-directed therapies for metastatic neuroendocrine tumors of the gastroenteropancreatic tract. Cancer Control 2011;18:127-137.

42 Naraev BG, Strosberg JR, Halfdanarson TR: Current status and perspectives of targeted therapy in well-differentiated neuroendocrine tumors. Oncology 2012;83:117-127.

43 Sethi G, Shanmugam MK, Ramachandran L, Kumar AP, Tergaonkar V. Multifaceted link between cancer and inflammation. Biosci Rep 2012;32:1-15.

44 Grivennikov SI, Greten FR, Karin M: Immunity, inflammation, and cancer. Cell 2010; 140:883-899.

45 Dougan M, Dranoff G: Immune therapy for cancer. Annu Rev Immunol 2009;27:83-117.

46 Landi S, Moreno V, Gioia-Patricola L, Guino E, Navarro M, de Oca J, Capella G, Canzian F; Bellvitge Colorectal Cancer Study Group: Association of common polymorphisms in inflammatory genes IL-6, IL-8, tumour necrosis factor- $\alpha$, NFKB1, and peroxisome proliferator-activated receptor- $\gamma$ with colorectal cancer. Cancer Res 2003;63:3560-3566.

47 Macarthur M, Hold GL, El-Omar EM: Inflammation and cancer. II. Role of chronic inflammation and cytokine gene polymorphisms in the pathogenesis of gastrointestinal malignancy. Am J Physiol Gastrointest Liver Physiol 2004;286:G515-G520.

48 Wimmel A, Wiedenmann B, Rosewicz S: Autocrine growth inhibition by transforming growth factor- $\beta_{1}$ in human neuroendocrine tumour cells. Gut 2003;52:1308-1316.

49 Nascimbeni R, Villanacci V, Di Fabio F, Gavazzi E, Fellegara G, Rindi G: Solitary microcarcinoid of the rectal stump in ulcerative colitis. Neuroendocrinology 2005;81:400-404.

50 Merchant SH, Van der Jagt T, Lathrop S, Amin MB: Sporadic duodenal bulb gastrin cell tumours: association with Helicobacter pylori gastritis and long-term use of proton pump inhibitors. Am J Surg Pathol 2006;30: 1581-1587.

51 Delle Fave G, Capurso G, Milione M, Panzuto F: Endocrine tumours of the stomach. Best Pract Res Clin Gastroenterol 2005; 19:659673.

52 Boltin D, Levi Z, Halpern M, Fraser GM: Concurrent small bowel adenocarcinoma and carcinoid tumor in Crohn's disease - case report and literature review. J Crohns Colitis 2011;5: 461-464.

- 53 Freeman HJ: Appendiceal carcinoids in Crohn's disease. Can J Gastroenterol 2003;17: 43-46. 
54 Okayasu I: Development of ulcerative colitis and its associated colorectal neoplasia as a model of the organ-specific chronic inflammation-carcinoma sequence. Pathol Int 2012; 62:368-380.

-55 De Visser KE, Eichten A, Coussens LM: Paradoxical roles of the immune system during cancer development. Nat Rev Cancer 2006;6: 24-37.

56 Lin WW, Karin M: A cytokine-mediated link between innate immunity, inflammation, and cancer. J Clin Invest 2007;11:71175-71183.

57 Fukuda A, Wang SC, Morris JP, Folias AE, Liou A, Kim GE, Akira S, Boucher KM, Firpo MA, Mulvihill SJ, Hebrok M: Stat3 and MMP7 contribute to pancreatic ductal adenocarcinoma initiation and progression. Cancer Cell 2011:19;441-455.

-58 Lesina M, Kurkowski MU, Ludes K, RoseJohn S, Treiber M, Klöppel G, Yoshimura A, Reindl W, Sipos B, Akira S, Schmid RM, Algül $\mathrm{H}$ : Stat3/Socs3 activation by IL- 6 transsignaling promotes progression of pancreatic intraepithelial neoplasia and development of pancreatic cancer. Cancer Cell 2011;19:456469.

-59 Yu H, Pardoll D, Jove R: STATs in cancer inflammation and immunity: a leading role for STAT3. Nat Rev Cancer 2009;9:798-809.

60 Yu H, Jove R: The STATs of cancer - new molecular targets come of age. Nat Rev Cancer 2004;4:97-105.

-61 Greten FR, Eckmann L, Greten TF, Park JM, Li ZW, Egan LJ, Kagnoff MF, Karin M: IKK $\beta$ links inflammation and tumorigenesis in a mouse model of colitis-associated cancer. Cell 2004;118:285-296.

62 Zhang H, Yao G: Progress in the study on colorectal cancer accompanied with neuroendocrine differentiation. Int J Pathol Clin Med 2009;29:537-540.

63 Huang S: Regulation of metastases by signal transducer and activator of transcription-3 signaling pathway: clinical implications. Clin Cancer Res 2007;13:1362-1366.

-64 Naugler WE, Karin M: NF- $\kappa$ B and canceridentifying targets and mechanisms. Curr Opin Genet Dev 2008;18:19-26.

65 Le Marc'hadour F, Bost F, Peoc'h M, Roux JJ, Pasquier D, Pasquer B: Carcinoid tumour complicating inflammatory bowel disease. A study of two cases with review of the literature. Pathol Res Pract 1994;190:1185-1192.

-66 Klöppel G, Clemens A: The biological relevance of gastric neuroendocrine tumours. Yale J Biol Med 1996;69:69-74.

67 Ruszniewski P, Delle Fave G, Cadiot G, Komminoth P, Chung D, Kos-Kudla B, Kianmanesh R, Hochhauser D, Arnold R, Ahlman H, Pauwels S, Kwekkeboom DJ, Rindi G; Frascati Consensus Conference; European neuroendocrine Tumor Society: Well-differentiated gastric tumours/carcinomas. Neuroendocrinology 2006;84:158-164.
68 Cadden I, Johnston BT, Turner G, McCance D, Ardill J, McGinty A: An evaluation of cyclooxygenase-2 as a prognostic biomarker in mid-gut carcinoid tumours. Neuroendocrinology 2007;86:104-111.

69 Abdul M, Hoosein N: Relationship of the interleukin-1 system with neuroendocrine and exocrine markers in human colon cancer cell lines. Cytokine 2002;18:86-91.

70 Sun MH. Neuroendocrine differentiation in sporadic CRC and hereditary non-polyosis colorectal cancer. Dis Markers 2004;20:283288.

71 Zhang L, Zhang WP, Hu H, Wang ML, Sheng WW, Yao HT, Ding W, Chen Z, Wei EQ: Expression patterns of 5-lipoxygenase in human brain with traumatic injury and astrocytoma. Neuropathology 2006;26:99-106.

72 Qian BF, El-Salhy M, Melgar S, Hammarstrom ML, Danielsson A: Neuroendocrine changes in colon of mice with a disrupted IL-2 gene. Clin Exp Immunol 2000;120:424-433.

73 Pavel ME, Hassler G, Baum U, Hahn EG, Lohmann T, Schuppan D: Circulating levels of angiogenic cytokines can predict tumour progression and prognosis in neuroendocrine carcinomas. Clin Endocrinol 2005;62:434-443.

74 Kulke MH, Lenz HJ, Meropol NJ, Posey J, Ryan DP, Picus J, Bergsland E, Stuart K, Tye L, Huang X, Li JZ, Baum CM, Fuchs CS: Activity of sunitinib in patients with advanced neuroendocrine tumors. J Clin Oncol 2008; 20:3403-3410.

75 Greenstein AJ, Balasubramanian S, Harpaz N, Rizwan M, Sachar DB: Carcinoid tumours and inflammatory bowel disease: a study of 11 cases and review of the literature. Am J Gastroenterol 1997;92:682-685.

76 Hsu EY, Feldman JM, Lichtenstein GR: Ileal carcinoid tumours simulating Crohn's disease: incidence among 176 consecutive cases of ileal carcinoid. Am J Gastroenterol 1997; 92:2062-2064.

77 Bassi A, Loughran C, Foster P: Carcinoid tumour of the terminal ileum simulating Crohn disease. Scand J Gastroenterol 2003;38:10041006.

78 Kasprzak A, Przewozna M, Zabel M, Pankowski J, Surdyk-Zasada J: Immunocytochemical analysis of the tissue location of cy tokines (IL-2 and IL-12) in neuroendocrine lung cancer. Folia Morphol 2003;62:301-303.

79 Cioffi U, De Simone M, Ferrero S, Ciulla MM, Lemos A, Contessini Avesani E: Synchronous adenocarcinoma and carcinoid tumour of the terminal ileum in a Crohn's disease patient. BMC Cancer 2005;5:157.

80 West NE, Wise PE, Herline AJ, Muldoon RL, Chopp WV, Schwartz DA: Carcinoid tumors are 15 times more common in patients with Crohn's disease. Inflamm Bowel Dis 2007;13: 1129-1134.

81 Barhoum M, Hutchins L, Fonseca VA: Intractable hypercalcemia due to a metastatic carcinoid secreting parathyroid hormone-related peptide and interleukin-6: response to octreotide. Am J Med Sci 1999;318:203-205.
82 Hollegaard MV, Bidwell J: Cytokine gene polymorphism in human disease: online databases, suppl 3. Genes Immun 2006;7:269276.

>83 Haukim N, Bidwell JL, Smith AJ, Keen LJ, Gallagher G, Kimberly R, Huizinga T, McDermott MF, Oksenberg J, McNicholl J, Pociot F, Hardt C, D’Alfonso S: Cytokine gene polymorphism in human disease: on-line databases, suppl 2. Genes Immun 2002;3:313330

84 Cigrovski Berkovic M, Jokic M, Marout J, Radosevic S, Zjacic-Rotkvic V, Kapitanovic S: IL-6 - $174 \mathrm{C} / \mathrm{G}$ polymorphism in the gastroenteropancreatic neuroendocrine tumours (GEP-NETs). Exp Mol Pathol 2007;83:474479.

85 Cigrovski Berkovic M, Jokic M, Marout J, Radosevic S, Zjacic-Rotkvic V, Kapitanovic S: IL-2 -330 T/G SNP and serum values - potential new tumour markers in neuroendocrine tumours of the gastrointestinal tract and pancreas (GEP-NETs). J Mol Med 2010;88:423429

86 Jensen RT, Berna MJ, Bingham DB, Norton JA: Inherited pancreatic endocrine tumor syndromes: advances in molecular pathogenesis, diagnosis, management, and controversies. Cancer 2008;113:1807-1843.

87 Chen M, Van Ness M, Guo Y, Gregg J: Molecular pathology of pancreatic neuroendocrine tumors. J Gastrointest Oncol 2012;3: $182-188$

88 Öberg K: The genetics of neuroendocrine tumours. Semin Oncol 2013;40:37-44.

-89 Chan AO, Kim SG, Bedeir A, Issa JP, Hamilton SR, Rashid A: CpG island methylation in carcinoid and pancreatic endocrine tumours. Oncogene 2003;22:924-934.

90 Massironi S, Sciola V, Peracchi M, Ciafardini C, Spampatti MP, Conte D: Neuroendocrine tumours of the gastro-entero-pancreatic system. World J Gastroenterol 2008; 14:53775384.

91 Franko J, Feng W, Yip L, Genovese E, Moser AJ: Non-functional neuroendocrine carcinoma of the pancreas: incidence, tumour biology, and outcomes in 2,158 patients. J Gastrointest Surg 2010;14:541-548.

-92 Berković M, Čačev, T, Zjačić-Rotkvić V, Kapitanović S: TNF-a promoter single nucleotide polymorphisms in gastroenteropancreatic neuroendocrine tumors. Neuroendocrinology 2006;84:346-352.

-93 Cigrovski Berkovic M, Catela Ivkovic T, Marout J, Zjacic-Rotkvic V, Kapitanovic S: Interleukin- $1 \beta$ gene single nucleotide polymorphisms and susceptibility to pancreatic neuroendocrine tumors. DNA Cell Biol 2012; 31:531-536.

94 Meric-Bernstam F, Gonzalez-Angulo AM: Targeting the mTOR signalling network for cancer therapy. J Clin Oncol 2009;27:22782287. 
95 Yao JC, Shah MH, Ito T, Lombard-Bohas C, Wolin EM, Van Cutsem E, Hobday TJ, Okusaka T, Capdevila J, de Vries EG, Tomassetti P, Pavel ME, Hoosen S, Haas T, Lincy J, Lebwohl D, Oberg K: Everolimus for advanced pancreatic neuroendocrine tumors. N Engl J Med 2011;364:514-523.

96 Raymond E, Dahan L, Raoul JL, Bang YJ, Borbath I, Lombard-Bohas C, Valle J, Metrakos P, Smith D, Vinik A, Chen JS, Horsch D, Hammel P, Wiedenmann B, Van Cutsem E, Patyna S, Lu DR, Blanckmeister C, Chao R, Ruszniewski P: Sunitinib malate for the treatment of pancreatic neuroendocrine tumors. N Engl J Med 2011;364:501-513.

-97 Vinik AI, Raymond E: Pancreatic neuroendocrine tumors: approach to treatment with focus on sunitinib. Ther Adv Gastroenterol 2013;6:396-411.
98 Bourcier ME, Sherrod A, DiGuardo M, Vinik AI: Successful control of intractable hypoglycemia using rapamycin in an 86-yearold man with a pancreatic insulin-secreting islet cell tumor and metastases. J Clin Endocrinol Metab 2009;94:3157-3162.

-99 Bourcier M, Vinik A: Sunitinib for the treatment of metastatic paraganglioma and VIPoma. Pancreas 2013;42:348-352.

100 O’Toole D, Couvelard A, Rebours V, Zappa M, Hentic O, Hammel P, Levy P, Bedossa P, Raymond E, Ruszniewski P: Molecular markers associated with response to chemotherapy in gastro-entero-pancreatic neuroendocrine tumors. Endocr Relat Cancer 2010;17:847-856
01 Mateo J, Heymach JV, Zurita AJ: Circulating biomarkers of response to sunitinib in gastroenteropancreatic neuroendocrine tumors: current data and clinical outlook. Mol Diagn Ther 2012;16:151-161.

102 Peng L, Schwarz RE: Pancreatic neuroendocrine tumors: signal pathways and targeted therapies. Curr Mol Med 2013;13:333-339.

103 Weber HC: Medical treatment of neuroendocrine tumours. Curr Opin Endocrinol Diabetes Obes 2013;20:27-31.

104 Siegfried Z, Bonomi S, Ghigna C, Karni R: Regulation of the Ras-MAPK and PI3KmTOR signalling pathways by alternative splicing in cancer. Int J Cell Biol 2013;1-9.

105 Fridman WH, Pagès F, Sautès-Fridman C, Galon J: The immune contexture in human tumours: impact on clinical outcome. Nat Rev Cancer 2012;12:298-306.

\section{Erratum}

In the article by Shin et al., entitled 'Hypothalamic and pituitary clusterin modulates neurohormonal responses to stress' [Neuroendocrinology 2013;98:233-241, DOI: $10.1159 / 000355625]$, the following errors have occurred in the Methods section, paragraph Immunohistochemistry and Immunofluorescence Staining:

'.. (1:2,000 for the pituitary gland, 1:1,000 for the hypothalamus, Santa Cruz; \#SC-H330) ...' should read

' $\ldots$ ( $1: 2,000$ for the pituitary gland, 1:1,000 for the hypothalamus, Santa Cruz; M18, SC6420) ...'

and

‘... (1:1,000, Santa Cruz; \#SC-H330) and anti- $\beta$-endorphin antibody (1:20,000; rabbit; Phoenix, Ariz., USA)...'

should read '...

(1:1,000, Santa Cruz; H330, SC-8354) and anti- $\alpha-M S H$ (sheep; Millipore AB5087; Billerica, Mass., USA) ...'.

We apologize for any inconveniences caused. 